\title{
Apolipoprotein and lipid abnormalities in chronic liver failure
}

A.C. Spósito ${ }^{1}$, C.G. Vinagre ${ }^{1}$, F.L. Pandullo², S. Mies², S. Raia ${ }^{2}$ and J.A.F. Ramires ${ }^{1}$

\author{
${ }^{1}$ Instituto do Coração and ${ }^{2}$ Unidade de Fígado, Hospital das Clínicas, \\ Faculdade de Medicina, Universidade de São Paulo, São Paulo, SP, Brasil
}

\begin{abstract}
Correspondence

A.C. Spósito

Divisão de Coronária

Instituto do Coração, FMUSP

Av. Dr. Eneas C. Aguiar, 44

05403-000 São Paulo, SP

Brasil

Fax: 55 (011) 881-5048

Publication supported by FAPESP.

Received May 7, 1996

Accepted August 26, 1997

Total serum lipids, as well as apolipoproteins A-I (apo A-I) and B (apo B), were determined in 74 patients with chronic liver failure without cholestasis and in 82 normal subjects. The VLDL, LDL and HDL lipid fractions were reduced in the liver failure group by $36 \%, 24 \%$ and $46 \%$, respectively $(\mathrm{P}<0.001)$. Apolipoproteins A-I and B were also reduced by $26 \%$ and $25 \%$, respectively $(\mathrm{P}<0.001)$. However, the reduction of HDL cholesterol (HDLc) was more pronounced than that of apo A-I and the HDLc:apo A-I ratio was significantly lower in the liver failure group. After separating these patients into groups with plasma albumin lower than 3.0, between 3.0 and 3.5, and higher than $3.5 \mathrm{~g} / \mathrm{dl}$, the HDLc:apo A-I ratio was proportional to plasma albumin, but the correlation was not statistically significant. When these patients were separated by the Child classification of liver function, there was a correlation between the HDLc:apo A-I ratio and liver function. The differences in the HDLc:apo A-I ratio between the Child groups $\mathrm{B}$ and $\mathrm{C}$, and $\mathrm{A}$ and $\mathrm{C}$ were statistically significant $(\mathrm{P}<0.05)$. We conclude that there is a more pronounced reduction in HDL cholesterol than in apo A-I in liver failure patients. Therefore, the HDLc:apo A-I ratio is a marker of liver function, probably because there is a decreased lecithin-cholesterol acyltransferase production by the diseased liver.
\end{abstract}

\section{Introduction}

Patients with non-cholestatic parenchymal liver disease with hepatic dysfunction have abnormal plasma lipid, apolipoprotein and lipoprotein structure and metabolism (16). These abnormalities are related to apolipoprotein, enzyme and lipid production. Therefore, a decrease in plasma apolipoprotein and lipid levels is positively correlated with the severity of liver failure $(3,7)$. Previous studies have compared the reduction of apolipoproteins (apo) A, C-II, C-III and E (1$4,7)$. The reduction in apo A-II is more pronounced than that in apo A-I, suggesting the existence of HDL with abnormal apolipo-
Key words

- Chronic liver disease

- Liver failure

- Apolipoprotein A

- Apolipoprotein B

- LCAT

- HDL cholesterol

- VLDL cholesterol

- Lipid metabolism protein composition or a more marked decrease in $\mathrm{HDL}_{3}$ than in $\mathrm{HDL}_{2}$ (1). The activity of lecithin-cholesterol acyltransferase (LCAT), the most important plasma cholesterol esterification enzyme, is directly related to plasma albumin and inversely related to liver dysfunction (5). Through its reduction, there is a low ester:free cholesterol ratio with cholesterol ester-poor lipoproteins $(5,6)$. In these patients, the lipoprotein composition is related to protein production and lipid metabolism.

In the present study, lipid and apolipoprotein profiles were compared between normal individuals and liver failure patients waiting for transplantation. The primary aim 
was to compare lipid and apolipoprotein reduction and to investigate their relation in normal and liver failure subjects.

\section{Patients and Methods}

We studied 74 consecutive patients with total bilirubin of less than $3 \mathrm{mg} / \mathrm{dl}$, admitted to the Instituto do Coração for admissional cardiac evaluation for liver transplantation, from January 1994 to June 1995 . There were 54 men and 20 women, mean age $48 \pm 8$ years, and the etiologies were $B$ and $C$ virus, and alcoholic and idiopathic disease. The control subjects included 82 individuals (42 men), mean age $57 \pm 10$ years, who had been referred to our hospital in 1994/1995 for cardiac catheterization for differential diagnosis of chest pain, but had no signs of coronary lesions (Table 1).

Subjects were admitted after a 12 -h overnight fast, and blood was collected from a forearm vein. Blood samples were allowed to clot at room temperature and serum was separated by centrifugation at $1500 \mathrm{~g}$ for 10 min and submitted to lipid and apolipoprotein determinations.

\section{Cholesterol and triglyceride assays}

Plasma cholesterol and triglycerides were determined by the method of Roschlau (7) and Bercolo and David (8), respectively. HDL cholesterol (HDLc) was determined by

Table 1 - Characteristics of the patients.

The liver failure patients were classified according to the Child classification (11).

\begin{tabular}{lcc}
\hline & Liver failure & Control \\
\hline Number & 74 & 82 \\
Gender (male/female) & $54 / 20$ & $42 / 40$ \\
Mean age (years) & $48 \pm 8$ & $57 \pm 10$ \\
Child A & $9(12.2 \%)$ & - \\
Child B & $33(44.6 \%)$ & - \\
Child C & $32(43.2 \%)$ & -
\end{tabular}

the same method used for total cholesterol after LDL and VLDL precipitation by the method of Warnick et al. (9). VLDL cholesterol (VLDLc) and LDL cholesterol (LDLc) were calculated by the formula of Friedwald et al. (10).

\section{Apolipoprotein assays}

Plasma apolipoproteins A-I and B were assayed by radial immunodiffusion on LipoPartigen R-Apo A-I and Nor-Partigen RApo B plates (Hoechst-Behring, RucilMalmaison, France).

In order to determine the change in cholesterol content of HDL lipoprotein, the HDLc:apo A-I ratio was compared between groups. The VLDLc and LDLc were correlated with apo B and HDLc with apo A-I in both groups.

\section{Statistical analysis}

Data were analyzed by the Student $t$-test and Mann-Whitney test for parametric and non-parametric data, respectively. The correlations were calculated by the Pearson Product Moment Correlation test and the level of significance was set at $\mathrm{P}<0.05$. The data are reported as means \pm standard deviation.

\section{Results}

All lipid profiles were significantly lower in the patients with liver failure (LF) than in the control group (Table 2). However, HDLc was more reduced in the LF group $(-46 \%)$ than in the control group. Since apolipoprotein A-I was also 26\% lower in the LF group, the HDLc:apo A-I ratio was lower in this group $(\mathrm{P}<0.0001)$. LDLc was $24 \%$ lower and apo B 25\% lower in the LF group. Furthermore, VLDLc was $36 \%$ lower in this group.

There was a positive correlation between HDLc and apo A-I in the LF group (correlation coefficient $=0.38$ and $\mathrm{P}<0.001$ ), but this 
was not the case for VLDLc and apo B, and LDLc and apo $\mathrm{B}$ in the two groups, and HDLc and apo A-I in the control group.

The patients were divided into three groups on the basis of plasma albumin levels: lower than $3.0 \mathrm{~g} / \mathrm{dl}$ (group 1), between 3.0 and $3.5 \mathrm{~g} /$ $\mathrm{dl}$ (group 2), and higher than $3.5 \mathrm{~g} / \mathrm{dl}$ (group 3), and the HDLc:apo A-I ratio was calculated for each group (Table 3). Plasma albumin was positively correlated with HDLc:apo A-I in all groups (correlation coefficient $=0.4,0.06$ and 0.3 for the groups 1,2 and 3, respectively; $\mathrm{P}<0.05)$. There was no statistically significant difference in the HDLc:apo A-I ratio between groups.

The patients were also divided by the Child classification of liver function (11) into $\mathrm{A}, \mathrm{B}$ and $\mathrm{C}$ groups. There was a positive correlation between the Child classification of each group and the respective HDLc:apo A-I ratio (correlation coefficient $=0.64,0.3$ and $0.27 ; \mathrm{P}<0.05)$. The differences in the HDLc:apo A-I ratio were statistically significant between the groups $\mathrm{A}$ and $\mathrm{C}$, and the groups $\mathrm{B}$ and $\mathrm{C}(\mathrm{P}<0.05)$ (Table 4).

\section{Discussion}

In the present study, lipoproteins, apolipoproteins and the HDLc:apo A-I ratio were compared in liver failure and control groups. We deliberately chose patients with bilirubin levels lower than $3.0 \mathrm{mg} / \mathrm{dl}$ to exclude patients with hyperbilirubinemia which interferes with colorimetric assays of plasma lipids. We also excluded patients with biliary cholestasis because of the known presence of large particles rich in free cholesterol and phospholipids in these patients that resemble LDL, the lipoprotein X $(5,12)$.

As also demonstrated by others $(5,13,14)$, plasma lipoprotein levels were lower in patients with liver failure than in the normal subjects. Apolipoproteins A and B were also about $26 \%$ lower in the LF group compared to the control group.

After a 12-h fast, the apo B lipoprotein cholesterol represents the VLDL plus LDL fractions. Plasma LDLc and apo B were lower in the LF group, showing a proportional reduction, but plasma VLDLc was $36 \%$ lower in this group. Although the specific mechanism is not known, the more pronounced reduction of VLDLc in the LF group may be explained by low LCAT activity. Day et al. (5) found that the VLDL lipoprotein from low activity LCAT patients

Table 2 - Plasma apolipoproteins ( $\mathrm{g} / \mathrm{l}$ ) and lipids (mg/ dl) of patients with chronic liver failure $(N=74)$ compared with control subjects $(N=82)$.

$\Delta \%=$ Percent reduction in the liver failure group ${ }^{*} \mathrm{P}<0.0003$ compared to control group (Student $t$-test and Mann-Whitney test)

\begin{tabular}{lcrl}
\hline & Liver failure & Control & $\Delta \%$ \\
\hline Apo A-I & $1.4 \pm 0.4^{*}$ & $1.9 \pm 0.9$ & $-26 \%$ \\
Apo B & $0.9 \pm 0.4^{*}$ & $1.2 \pm 0.3$ & $-25 \%$ \\
Cholesterol & $134 \pm 38^{*}$ & $194 \pm 41$ & $-31 \%$ \\
Triglycerides & $80 \pm 35^{*}$ & $126 \pm 67$ & $-36.5 \%$ \\
HDLc & $25 \pm 15^{*}$ & $46 \pm 12$ & $-46 \%$ \\
LDLC & $93 \pm 28^{*}$ & $122 \pm 36$ & $-24 \%$ \\
VLDLC & $16 \pm 7^{*}$ & $25 \pm 13$ & $-36 \%$ \\
HDLc:apo A-I & $19 \pm 12^{*}$ & $29 \pm 13$ & $-34 \%$
\end{tabular}

Table 3 - HDLc:apo A-I ratio in patients with chronic liver failure as a function of serum albumin levels (g/dl).

Albumin groups: 1) <3.0; 2) 3.0-3.5; 3) >3.5.

\begin{tabular}{lcccc}
\hline & Group 1 & Group 2 & Group 3 \\
\hline Number & 22 & 30 & 22 \\
Albumin & $2.7 \pm 0.3$ & $3.3 \pm$ & 0.1 & $3.9 \pm 0.2$ \\
HDLc:apo A-I & $15.5 \pm 6.8$ & $17.6 \pm 12.9$ & $22.3 \pm 14.6$
\end{tabular}

Table 4 - HDLc:apo A-I ratio in patients with chronic liver failure according to the Child classification.

$\mathrm{P}<0.05$ between the Child $\mathrm{A}$ and $\mathrm{C}$, and $\mathrm{B}$ and $\mathrm{C}$ groups (Student $t$-test).

\begin{tabular}{lccc}
\hline & Child A & Child B & Child C \\
\hline Number & 9 & 33 & 32 \\
HDLc:apo A-I & $22 \pm 15$ & $18 \pm 8$ & $12 \pm 5$
\end{tabular}


has high protein and triglyceride levels, and low phospholipid, free cholesterol and cholesteryl ester concentrations. These investigators reported a positive correlation between LCAT activity and total VLDL.

On the other hand, since HDLc was more markedly reduced than apo A-I in the LF group, the HDLc:apo A-I ratio was significantly lower in these patients than in normal subjects. Therefore, although apo A-I reduction was similar to apo $\mathrm{B}$, the cholesterol content of HDL in the LF group was lower than in the control group. In contrast, the HDL lipoprotein of the LF group was poor in cholesterol ester. After the patients were divided into three groups according to plasma albumin, and by the Child classification, the HDLc:apo A-I ratio was proportional to liver function. However, there was no statistically significant difference in the HDLc:apo A-I ratios for each albumin group or between the Child B and C groups, perhaps because of the small number of patients of each subgroup.
Since there is synthesis of apo A-I and HDL lipoprotein, the presence of cholesterol-poor particles can be explained by cholesterol esterification. With the reduction of esterification, the free cholesterol captured on the surface of HDL was not esterified and did not return to the tissues. A similar transport of free cholesterol molecules from HDL to cells has been reported in LCAT deficiency patients (15). The early reduction of LCAT activity in liver failure as reported by Simon and Scheig (6) should explain this ratio of HDLc to apo A-I.

In conclusion, as shown in other reports, plasma apolipoproteins as well as the lipids in non-cholestatic parenchymal liver disease with hepatic failure are below the levels of normal individuals. The decrease in HDL cholesterol in these patients was more pronounced than the decrease in apo A. The reduced production of enzymes such as LCAT may explain the composition of HDL and VLDL lipoproteins in these patients.

\section{References}

1. Fujii S, Koga S, Shono T, Yamamoto K \& Ibayashi H (1981). Serum apoprotein A-I and $A-I I$ levels in liver diseases and cholestasis. Clinica Chimica Acta, 115: 321-331.

2. Rubies-Prat J, Masdeu S, Nubiola AR, Chacon P, Holguera C \& Masana L (1982). High-density lipoprotein cholesterol and phospholipids, and apoprotein A in serum of patients with liver disease. Clinical Chemistry, 28: 525-527.

3. Koga S, Yamamoto K \& Ibayashi H (1984). Alterations in levels of apolipoprotein C-III and $\mathrm{C}-\mathrm{II} / \mathrm{C}-\mathrm{III}$ ratios in patients with liver disease. Gastroenterologia Japonica, 19: 65-71.

4. Perales J, Angel Lasuncion M, Cano A, Martin-Scapa MA, Maties M \& Herrera E (1994). Changes in the lipid profile in chronic hepatopathies. Medical Clinics of North America, 102: 364-368.

5. Day RC, Harry DS, Owen JS, Foo AY \& Mclntyre N (1979). Lecithin-cholesterol acyltransferase and lipoprotein abnormalities of parenchymal liver disease. Clinical Science, 56: 575-583.
6. Simon JB \& Scheig R (1970). Serum cholesterol esterification in liver disease. New England Journal of Medicine, 283: 841846.

7. Roschlau P (1975). 9th International Congress of Clinical Chemistry, Toronto, Abstract No. 1. Tunder P. Annals of Clinical Biochemistry, 1969, 6: 24. Apud: Merck (Rio de Janeiro). Cholesterol Chod-Pap: Método colorimétrico enzimático (Artigo No. 172, 626-bula).

8. Bercolo G \& David H (1973). Quantitative determination of serial triglycerides by the use of enzymes. Clinical Chemistry, 19: 476-482.

9. Warnick GR, Cheung MC \& Albers JJ (1979). Comparison of current methods for high density lipoprotein cholesterol quantification. Clinical Chemistry, 25: 596604.

10. Friedwald WT, Levy RI \& Fredrickson DS (1972). Estimation of low-density lipoprotein cholesterol in plasma without use of preparative ultracentrifuge. Clinical Chemistry, 18: 499-502.
11. Albers I, Hartmann $H$, Bircher $J$ \& Creutzfeldt W (1989). Superiority of the Child-Pugh classification to quantitative liver function tests for assessing prognosis of liver cirrhosis. Scandinavian Journal of Gastroenterology, 24: 269-276.

12. Seidel D, Alaupovic $P$, Furman $R H$ \& McConathy WJ (1970). A lipoprotein characterizing obstructive jaundice. Journal of Clinical Investigation, 49: 2396-2407.

13. Vergani C, Trovato G, Delu A, Pietrogrande M \& Dioguardi N (1978). Serum total lipids, lipoprotein cholesterol and apolipoprotein $A$ in acute viral hepatitis and chronic liver disease. Journal of Clinical Pathology, 31: 772-778.

14. Agorastos J, Boswell C, Harry DS \& Mclntyre N (1976). Plasma lipoproteins in liver disease. Biochemical Society Transactions, 4: 593-596.

15. Eisenberg S (1984). High density lipoprotein metabolism. Journal of Lipid Research, 25: 1017-1054. 